\title{
El ciberracismo: una paradoja en la lucha afrodescendiente
}

\author{
Andrés Felipe Leguizamón, \\ Erika Viviana Guataquí, \\ Jessica Paola Rivera López ${ }^{\mathrm{I}}$
}

\section{Introducción}

En Colombia históricamente el color de piel ha influido notablemente en lo político, social y cultural, por lo cual ser moreno en ese entonces implicaba ser considerado máquina u objeto de trabajo y sexualidad, todos estos estereotipos continúan siendo reproducidos a través de los discursos sociales y de los medios de comunicación digitales, de acuerdo con Jesús Martín Barbero, al igual que los medios tradicionales, "las tecnologías no son neutras pues hoy más que nunca ellas constituyen enclaves de condensación e interacción de intereses económicos y políticos con mediaciones sociales y conflictos simbólicos. Pero por eso mismo ellas son constitutivas [...] de las nuevas forma de ciudadanía..."(2002, p. 18).

De manera que la internet ha cambiado la forma de relacionarse entre los seres humanos, el auge que tienen las redes sociales ha hecho que tanto hombres como mujeres tengan una participación activa entre ellos, esto establece que las tecnologías jueguen un papel fundamental y trasformador, debido a que constituye distintas posibilidades comunicativas de tal manera que logra trasmitir la información en varios canales con una gran cantidad de contenidos.

1 Estudiantes de la Facultad de Comunicación Social de la Universidad Santo Tomás. 
Es así como el desarrollo de las nuevas tecnologías de la información y comunicación (TIC) en especial las redes sociales y la internet han tenido un alto impacto en cuanto a la discriminación racial que es empleada por los diversos usuarios de la red, puesto ha proporcionado un espacio en el cual se puede expresar y tener un sin número de perspectivas en donde la pluralidad de voces manifiestan lo que piensan, por lo que a través de las redes sociales se ha proliferado los contenidos excluyentes, produciendo nuevas formas y dimensiones de marginación hacia la población afro, aumentando a menudo la discriminación en línea.

Por tanto en Colombia se puede dar cuenta de estas prácticas discriminatorias mediáticas en donde la diseminación de estos estereotipos configuran nuevas ciudadanías basadas en lo mediático, siendo así que el discurso racista mediado a través de las redes sociales, las cuales están inmersas en lo que hoy en día se considera "era digital", ha sido utilizado por los individuos para expandir de manera masiva la discriminación de los afrodescendientes.

Una red social muy conocida y popular a nivel global es Facebook, cuenta con 1650 millones de usuarios activos los cuales se comunican, comparten e intercambian contenidos a múltiples lugares del mundo, siendo así que por medio de las fotos, memes o imágenes publicadas se ha creado un contenido racista y altamente estereotipado, en donde se implantan posiciones, se construyen mensajes y se vuelve viral la transmisión de estos discursos racistas.

En relación a los casos que se observan en Facebook de exclusión y marginación, es importante identificar y denunciar a los mecanismos de autorregulación y sanción de esta red social, ya que según la política de Facebook, no permite que individuos ni grupos de personas ataquen a nadie por su raza, grupo étnico, nacionalidad, religión, orientación sexual, discapacidad o enfermedad. Por esta razón, cualquier contenido que contravenga esta norma podrá ser reportado y eliminado por Facebook.

Sin embargo, muchos individuos publican todo tipo de contenidos racistas de forma anónima ya que, crean varias cuentas o cambian y falsifican su identidad con el objetivo de no tener ningún castigo o restricción, esto genera que haya una impunidad en la mayoría de los 
casos, afectando principalmente a las personas afrodescendientes que se encuentran inmersas en videos o imágenes discriminatorias.

\section{Análisis de casos en la red}

Las redes sociales con el pasar del tiempo se han convertido en espacios que ayudan a compartir conocimiento e información personal, los diferentes usos que nos otorga la internet son infinitos, en los que de una u otra manera podemos compartir contenidos de gran importancia o en otros casos algunos son utilizados en calidad de discurso para divulgar información de carácter racista, xenófobo y discriminatorio.

En las redes sociales, la modalidad de racismo se ha centrado en las características biológicas de las personas a la hora de interponer una jerarquización entre una etnia, las relaciones interpersonales y la divulgación de información personal en las redes de comunicación en el internet.

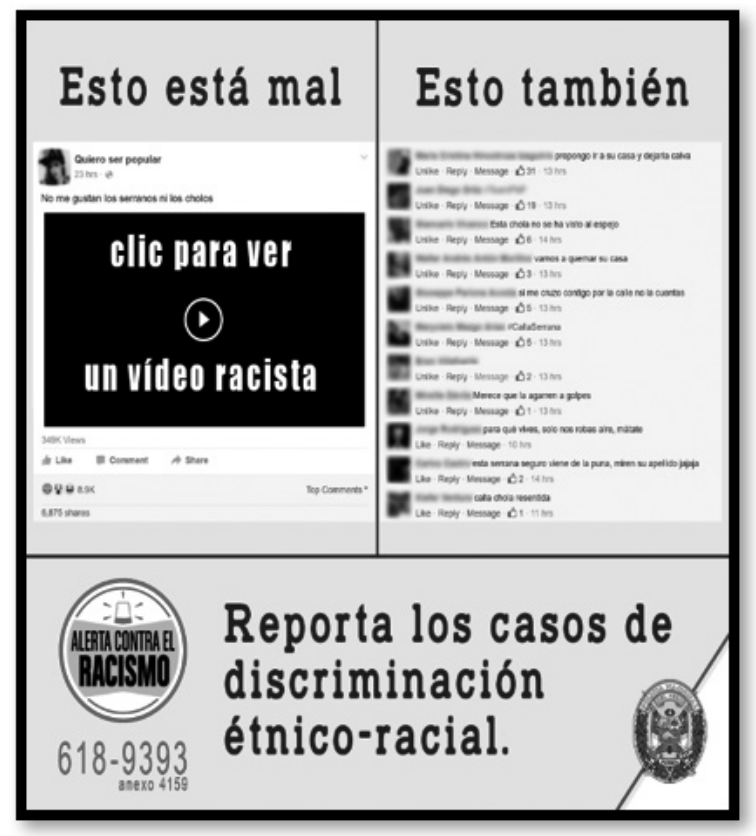

Fuente: El Comercio, (2017). Tomado de http://elcomercio.pe/redes-sociales/facebook/ facebook-pnp-recomienda-que-hacer-ante-publicacion-racista-noticia-1897574 
Video en el que una persona afrodescendiente se ofusca por la discriminación que sufre por parte de la Policía.

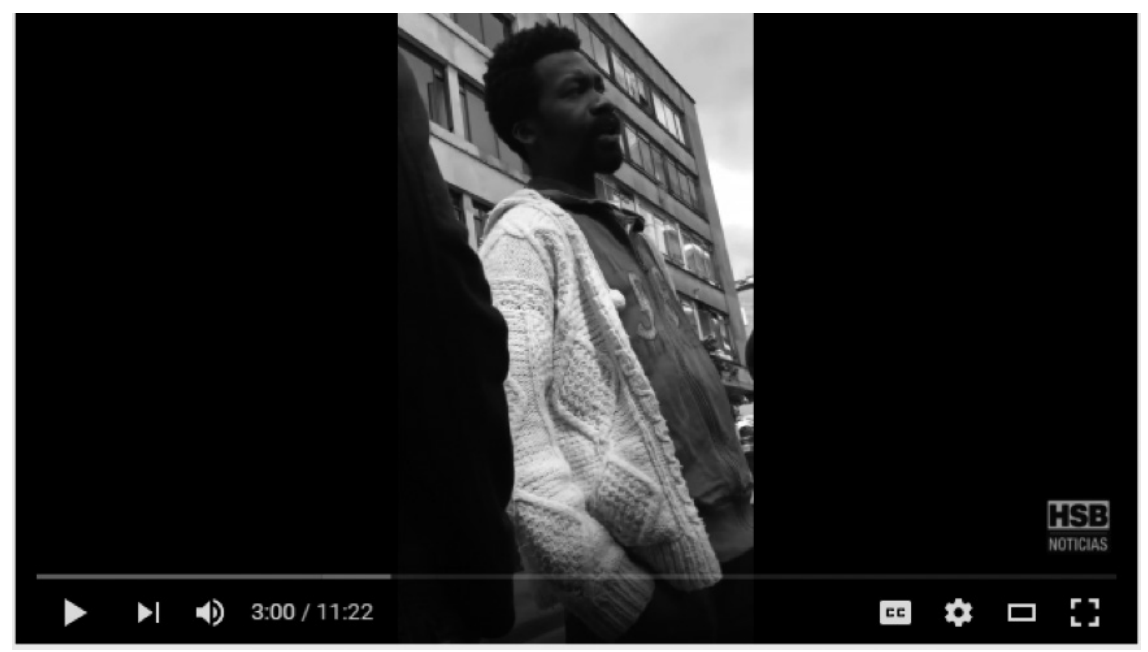

Fuente: tomado de YouTube. 2015/09/15

El concepto de ciudadanía se remonta varios siglos atrás y se vincula con el desarrollo de la cultura moderna y del pensamiento. Un gran reconocimiento de esta historia logra remontarse y basarse en la exclusión que la noción de ciudadanía conllevaba.

Con el fortalecimiento del Estado - Nación se logra estructurar la moderna sociedad civil y por ende una ciudadanía y ciudadano característico.

Durante los siglos XIX y Xx se puede reconocer el desarrollo de la concepción moderna de ciudadanía y así poder diferenciar tres etapas que son fundamentales en el reconocimiento de las instituciones y de los derechos que fueron creados, entre esos: política, social y legalmente.

Siendo esto así el caso de Carlos Alberto Angulo Góngora quien en un video subido a la red el cual dura aproximadamente 2 minutos con 20 segundos en donde no solo se nota su furia, sino donde también se gana el respeto de los espectadores del video y de las personas que circulaban por las calles de Bogotá que presenciaron este hecho en donde Carlos comenzó a mostrar el afán de sus raíces históricas y el ser ciudadano por la constante discriminación racial que ha venido sufriendo y en particular en este caso en el que dos patrulleros de 
la Policía lo abordan para pedirle sus papeles y realizarle una requisa llamándolo "negro", lo que desencadenó la fuerte reacción de esta persona argumentado:

“¿Por qué a ellos no los requisás? Porque son blancos, son ciudadanos, son de esta ciudad y no representan un peligro. Parás a los dos negros, esto implica que llegaré tarde al trabajo y tendré problemas con mi patrón".

De inmediato este video fue subido a Facebook por uno de los transeúntes y en menos de nada se viralizó en las diferentes redes sociales, dejando en evidencia la fuerte discriminación racial que siguen viviendo estas personas y por ende se impide el progreso de millones de personas en todo el mundo.

Video en el que un taxista afrodescendiente es agredido por una mujer.
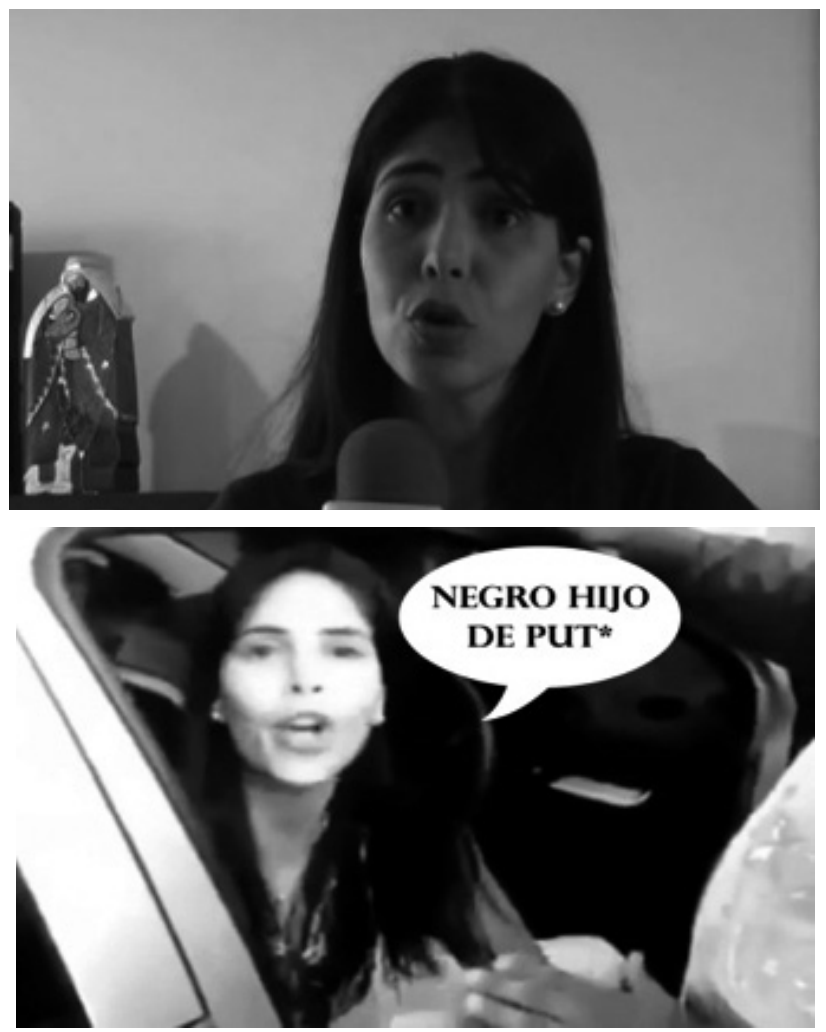

Fuente: tomado de Google 
Otro de los casos más virales de las redes sociales, se presentó en Cartagena en donde la mayoría de sus habitantes es negra y en donde gran parte de la población no es reconocida como tal.

Este incidente fue protagonizado por un taxista quien conducía por las calles de Cartagena cuando chocó su vehículo con el de una mujer en un barrio popular de La Heroica, la mujer enfurecida comenzó a lanzar palabras soeces contra el taxista, quien decide grabar a la mujer insultándolo y refiriéndose a él como "negro".

Es evidente que en una ciudad como lo es Cartagena que pasó por una etapa de años en el que el flagelo era la esclavitud contra los negros, la gente que comentó y observo el video asegura que no se puede permitir que el racismo siga siendo parte de la historia de Colombia, es una etapa que debe quedar atrás en una sociedad en la que las huellas del pasado no se han querido borrar.

Video en el que una revista reconocida discrimina a mujeres afrodescendientes.

EE NOTICIAS $\checkmark$ OPINION ECONOMIA DEPORTES ENTRETENIMIENTO VIVIR MUER TECNOLOGIA BLOGS

Home

POLITICA 7 DIC 2011 7.04 AM

Advierten terrible caso de discriminación racial en Cali

El senador Carlos Baena, autor de la ley antidiscriminación racial, reprocho las fotografias donde dos afrocolombianas trabajan como 'adornos' en una casa para demostrar la supremacia racial.
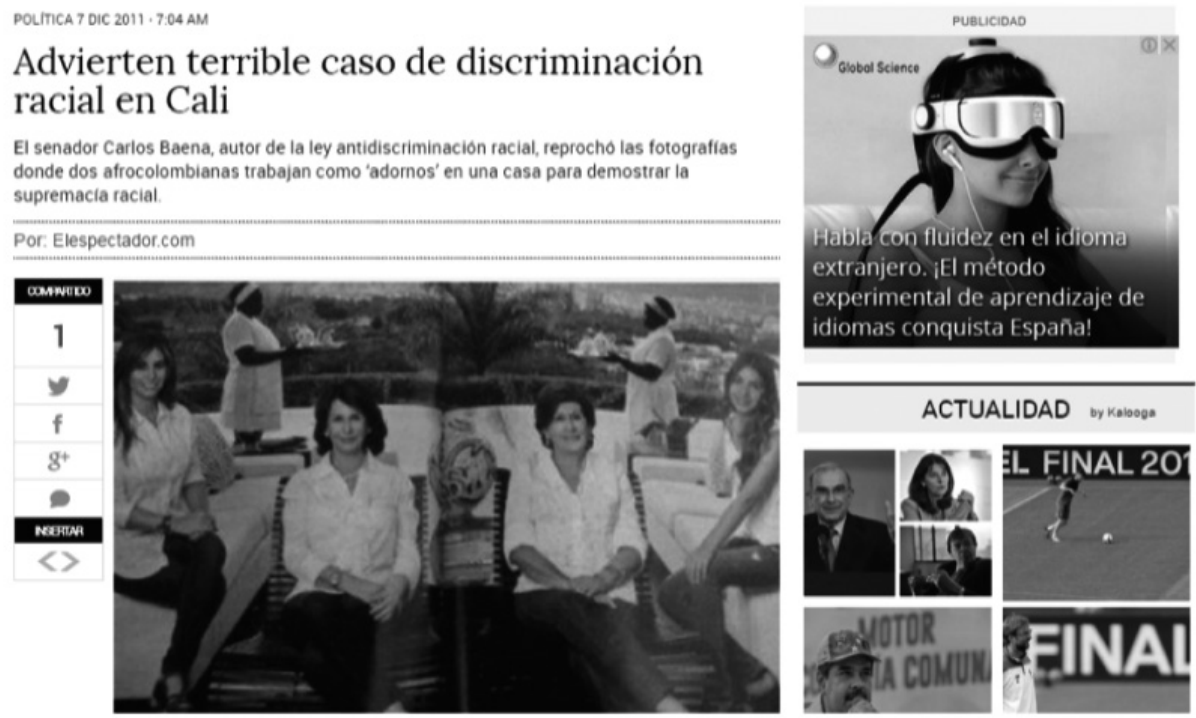

Fuente: tomado de El Espectador, 2011 
La ciudadanía tiene que ver con obligaciones y derechos que van ligados con el Estado y la responsabilidad frente y para la sociedad. Esta noción logra incluir un conjunto de prácticas que constituyen a los individuos como seres competentes de una comunidad generando estas mismas de carácter social, legal, cultural y político.

Se logra involucrar la idea de una estructura nacional de la política con un estatus común, en donde se quiere incluir una cultura común en donde cada uno de los ciudadanos puedan participar igualitariamente, donde este este activo en la vida pública y donde pueda someter sus intereses generales a la sociedad.

Evidentemente en esta publicación hay una brecha grande de desigualdad y de irrespeto frente a la comunidad afrocolombiana, quienes aparecen en esta foto publicada por un medio muy reconocido a nivel nacional, donde aparecen dos trabajadoras afrodescendientes laborando para una prestigiosa familia en la ciudad de Cali.

Dicha publicación fue repudiada por miles de usuarios en las redes sociales e incluso representantes del Congreso de la República como el senador Carlos Alberto Baena López autor de la Ley de Discriminación, quien hizo un llamado a todos los colombianos para que respeten a las minorías del país:

"Es un compromiso de todos los ciudadanos ayudar a la convivencia con respeto"

Este señalamiento por parte del senador dejo claro en el Congreso que quien obstruya, restrinja e impida en pleno ejercicio los derechos de las personas por razones de nacionalidad, etnia, sexo u orientación sexual, sería castigado con 3 años de prisión y multas de 8 millones de pesos.

\section{Entorno jurídico}

La lucha frente a todo acto discriminatorio se ha remontado a décadas, lo que bajo sucesos históricos y la misma unión de los sectores minoritarios afectados conllevó a la creación de instrumentos jurídicos internacionales y nacionales para sobrellevar los actos de marginalidad.

En un contexto global, tras la segunda guerra mundial y el establecimiento de la Organización de Naciones Unidas (ONU) en 1945 que 
conllevó a la postulación y ejecución de una legislación internacional direccionada a la regulación y prohibición de cualquier acto discriminatorio colectivo u individual, se valió de otros instrumentos jurídicos decretados en los que se resalta:

- La declaración universal de los derechos humanos en 1948.

- Convención Internacional sobre la Eliminación de todas las formas de Discriminación Racial de las Naciones Unidas en 1965.

- Pacto Internacional de los Derechos Civiles y Políticos en 1966

Todas vigiladas desde la asamblea general de las Naciones Unidas como institución responsable de velar por los derechos y libertades fundamentales, sin exclusión por raza, sexo, religión u idioma, además de en 1978 haber realizado la primera conferencia mundial para combatir la discriminación racial, en la cual se afirmó:

- Toda doctrina de superioridad racial es científicamente falsa, moralmente condenable.

- Todos los pueblos y todos los grupos humanos han contribuido al progreso de la civilización, y las culturas que constituyen el patrimonio común de la humanidad.

- Todas las formas de discriminación, basadas en la teoría de la superioridad, la exclusividad o el odio raciales son una violación de los derechos humanos fundamentales.

En Colombia, la construcción de herramientas jurídicas contra el racismo y la discriminación inició con la constituyente de 1991, donde a través de la participación de la comunidad afrodescendiente se logró establecer y dar origen a la Ley 70 de 1993, la cual básicamente reconoció la presencia de comunidades negras en algunas partes del país, y además, protegió la identidad cultural y derechos de las minorías en el país.

Sin embargo, tras un historial de intolerancia después de las normas jurídicas, se estableció el 30 de noviembre de 2011 una segunda 
herramienta jurídica estipulada en la Ley 1482, por la cual se modifica el código penal colombiano y que por medio de su decreto tiene como objetivo garantizar la protección de los derechos fundamentales de una persona u colectivo que se vea afectado por actos de racismo o discriminación. De forma más específica se afirma dentro de la Ley 1482 de 2011 en los artículos:

ARTíCULO 3o. El Código Penal tendrá un artículo $134^{\mathrm{a}}$ del siguiente tenor:

Artículo 134A. Actos de Racismo o discriminación. El que arbitrariamente impida, obstruya o restrinja el pleno ejercicio de los derechos de las personas por razón de su raza, nacionalidad, sexo u orientación sexual, incurrirá en prisión de doce (12) a treinta y seis (36) meses y multa de diez (10) a quince (15) salarios mínimos legales mensuales vigentes.

ARTíCUlO 4o. El Código Penal tendrá un artículo 134B del siguiente tenor:

Artículo 134B. Hostigamiento por motivos de raza, religión, ideología, política, u origen nacional, étnico o cultural. El que promueva o instigue actos, conductas o comportamientos constitutivos de hostigamiento, orientados a causarle daño físico o moral a una persona, grupo de personas, comunidad o pueblo, por razón de su raza, etnia, religión, nacionalidad, ideología política o filosófica, sexo u orientación sexual, incurrirá en prisión de doce (12) a treinta y seis (36) meses y multa de diez (10) a quince (15) salarios mínimos legales mensuales vigentes, salvo que la conducta constituya delito sancionable con pena mayor.

Sin embargo, ante el limbo jurídico dentro de esta ley, se evidencia la falta de penalización a los actos descritos como cibernéticos, y en sí, de reglamentación ante actos y acciones discriminatorias, racistas o peyorativas en el internet dando pie, y falta de argumento legislativo, al deber actuar de la ley colombiana en algunos casos considerados racistas que se desviven del plano físico, considerándose así como un 
delito informático y lo que se sugiere como medidas aludiendo a lo más común: Phishing o suplantación de páginas.

\section{Conclusiones}

La internet es una herramienta que en esta "era digital" es utilizada por los individuos para consumir e intercambiar miles de contenidos e información, es así que una de las redes más conocidas y visitadas por distintas personas es Facebook, esta plataforma ha tenido un efecto negativo en cuanto a que se han creado grupos xenofóbicos que debido a la libertad que les brinda esta red exponen su rechazo hacia determinado grupo étnico de manera discriminativa, haciendo que estos contenidos vistos en la red sean expandidos y puestos a disposición de diversos usuarios, donde el degradar a las personas afrodescendientes ha sido el objetivo de algunas personas que son racistas.

La estrecha relación entre el discurso de la intolerancia y los crímenes de odio son una clara evidencia de cómo hasta hoy se ha logrado consolidar una problemática preocupante de normalización de "sites" de intolerancia en los diferentes portales web como; chats, blogs, newgroups.

Por otro lado, este discurso no es un tema nuevo en cuanto al debate de los derechos humanos, su dimensión on-line y el impacto gigantesco que tienen dan nuevos motivos de preocupación y alerta entre los jóvenes usuarios que usan la internet con más frecuencia. Mientras es un poco más fácil contrarrestar y controlar en los diferentes y principales medios de comunicación, en este caso las redes y los desafíos que se han planteado nos enseña la capacidad para controlar y medir la amplitud e impacto que causa la discriminación racial por redes.

La lucha contra esta problemática es necesaria y debe empezar por preguntarse cómo intervenir al respecto. Su respuesta claramente ha de hacerse educando desde este medio de comunicación que actualmente es bastante usado por millones de usuarios y denunciando con los instrumentos democráticos del Estado de derecho frente a los miles de casos de racismo que se presentan por día, por lo que conviene no olvidar: "Lo que es ilegal fuera de la red, también lo es en internet", es así que se puede dejar como interrogante si Colombia sigue siendo 
un país racista y lleno de prejuicios en donde las distintas redes ahora son canales por los cuales se propaga la discriminación contra los afrodescendientes.

Cabe resaltar que dentro de la legislación colombiana es muy explícita a la hora de particularizar los casos en los que se acusa de racismo y discriminación, su espacio de acción a la hora de hablar de medidas legales en el manejo y control de estas expresiones en la red y el cibermundo llega a ser casi nulo, siendo así que la poca efectividad a la hora de reaccionar frente a estas páginas o personas, este tipo de actos inmersos en la red no sean percibidos de forma ilegal o de delito informático hacia los causantes. Es entonces, cuando es pertinente pensar en formas de respuesta o la inclusión de nuevas políticas públicas enfocadas a estos nuevos campos para su regulación.

\section{Referencias}

Barbero, Jesús Martín. (2002). Tecnicidades, identidades, alteridades: desubicaciones y opacidades de la comunicación en el nuevo siglo. En: Diálogos de la Comunicación 15. 8-29.

Corte constitucional. (2013). Demanda de inconstitucionalidad contra la Ley 1482 de 2011, "por medio de la cual se modifica el Código Penal y se establecen otras disposiciones”. Referencia: expedientes D-8992. Sentencia C-282/13

El Comercio. (30 de abril 2016). Facebook: PNP explica qué hacer ante un caso de racismo. Recuperado de http://elcomercio.pe/redes-sociales/facebook/facebook-pnp-recomienda-que-hacer-ante-publicacion-racista-noticia-1897574

ODCR. (s.f). Ley 1482: Herramienta jurídica contra el Racismo y la Discriminación. Recuperado de http://observatoriocdr.gov.co/index.php/ politicas-publicas/politicas-publicas-infancia-y-ninez/10-politicas-publicas-infancia-y-ninez/26-ley-1482-herramienta-juridica-contra-el-racismo-y-la-discriminacion

YouTube. (2017). Afro denuncia presunto "racismo" por Policía de Bogotá. [online] Recuperado de https://www.youtube.com/watch?v=_wleOYnofOA [Accessed 6 Apr. 2017]. 
